\title{
Variation in plasma leptin levels in young Iranian children with cystic fibrosis
}

Maryam Monajemzadeh ${ }^{1}$, Mohammad Taghi Haghi Ashtiani ${ }^{1}$, Ehsan Sadriann ${ }^{1}$, Sedigheh Shams ${ }^{1}$, Farzaneh Motamed ${ }^{2}$, Mehri Najafi Sani ${ }^{2}$, Setareh Sadat Banihosseini', Ata Abbasi ${ }^{1}$

\begin{abstract}
1Department of Pathology, Children Medical Center Hospital, Tehran University of Medical Sciences, Keshavarz Boulevard, Tehran, Iran

2Department of Pediatric Gastroenterology, Children Medical Center Hospital, Tehran University of Medical Sciences, Keshavarz Boulevard, Tehran, Iran
\end{abstract}

Submitted: 9 October 2011

Accepted: 2 February 2012

Arch Med Sci 2013; 9, 5: 883-887

DOI: 10.5114/aoms.2013.38683

Copyright $\odot 2013$ Termedia \& Banach

\section{Abstract}

Introduction: Poor weight gain is one of the most important mortality hazards in cystic fibrosis (CF) patients. The mechanisms that may hinder body weight regulation are not completely understood. Leptin and its role in fat mass could be related to control of weight gain in CF patients. As the previous data are conflicting, we aimed to investigate serum leptin level in Iranian CF children compared to a control group.

Material and methods: Forty-three CF patients aged from 3 to 120 months and 43 age-matched controls were enrolled. Patients were recruited from the outpatient clinic of the Children's Medical Center Hospital. Controls were visited in the general outpatient clinic for an annual check-up. Both groups were divided into three subgroups based on age: 3 to 12 months, 13 to 48 months, and 49 to 120 months. Body mass index (BMI) was calculated for all the participants. Serum leptin levels were measured applying a solid phase enzyme-linked immunosorbent assay (ELISA).

Results: Leptin levels and BMI values were significantly different between patients and controls ( $p=0.02, p<0.001$, respectively) but only patients aged 13-48 months had significantly higher levels of leptin than age-matched controls $(p=0.016)$. Overall male patients' mean leptin level was significantly higher than in female patients $(p=0.032)$ and male controls $(p<0.001)$.

Conclusions: Leptin level in our patients was significantly higher than controls. It seems that leptin levels during infancy are higher than in adult patients. Further studies are required on specific genotypes, gender and age to reveal the probable correlation with BMI and leptin levels in CF patients from different ethnic groups.

Key words: leptin, children, cystic fibrosis, body mass index, Iran.

\section{Introduction}

Despite improvements in management of children with cystic fibrosis (CF) over the last decades $[1,2]$ there are still significant differences in mean height, weight and body mass index (BMI) of patients compared to healthy individuals [3]. In fact, chronic energy deficiency is still the most important mortality hazard beside pulmonary problems. The mechanisms that may hinder energy balance coordination and body weight regulation are not completely understood in CF. Decreased appetite and weight loss

\author{
Corresponding author: \\ Maryam Monajemzadeh MD \\ Pathology Department \\ Children Medical \\ Center Hospital \\ Tehran University \\ of Medical Sciences \\ Keshavarz Boulevard \\ Tehran, Iran \\ Phone: +98 2166922115 \\ Cell phone: +98 9122148534 \\ E-mail: \\ monajemz@sina.tums.ac.ir
}


are partly associated with altered energy metabolism and increased activation of the inflammatory system $[4,5]$ through the action of several peptide hormones on hypothalamic pathways [6].

Leptin, discovered in 1994, is a pro-inflammatory inducer hormone $[7,8]$ primarily known for its inhibitory role in food intake $[9,10]$. Leptin is a 16$\mathrm{kDa}$ non-glycosylated polypeptide encoded by the obesity (ob) gene [11]. It is secreted by adipocytes in the fat tissue [8]. Leptin circulatory levels activate specific receptors in the hypothalamus. Consequently, a decrease in food intake and an increase in energy consumption would regulate body energy reserves and decrease in leptin causes uncontrolled food intake and resulting obesity [12-14]. Apart from having a regulatory role in energy homeostasis, leptin is also a cytokine-like hormone with pleiotropic actions. It is shown to have a function in a wide range of interactions and pathways such as glucose metabolism, glucocorticoids synthesis, immunologic reactions, and hormone axis regulation [14-17].

Leptin levels may reflect the amount of body fat that may be altered in anorexia or obesity [18]. The relationship between leptin and fat mass could be an additional factor in weight loss or poor weight gain in CF patients [19].

Previous studies performed in America and Europe resulted in conflicting data about the physiologic regulation or dysregulation of leptin synthesis in CF patients compared to controls [5, 19-23]. These six studies assessed CF patients in different age groups and different clinical statuses. Increased levels of leptin were found in children with CF as compared to healthy children in two studies in the United Kingdom and Greece [19, 20], while in CF children in another study performed in Brazil, leptin levels were lower than in controls [21].

No difference in leptin levels was found between cases and controls in a study on adult CF patients [22]. Another study by Cohen et al. demonstrated lower leptin levels in advanced CF patients than mild or moderate CF patients and controls that could be a consequence of weight loss and not a cause of that [5]. Leptin was also lower in CF patients homozygous for $\triangle \mathrm{F} 508$ mutations (143 years old) [23]. The previous data are conflicting and there is no record of Iranian patients' leptin levels to date.

In this study we compared serum leptin level in Iranian CF children with an age- and sex-matched control group to see if there is any association of these hormones with the BMI and other demographic parameters.

\section{Material and methods}

This study was approved by the ethics committee of Tehran University of Medical Sciences. The study was explained to the patients and informed written consent was obtained from all patients' respective parents. Blood samples for leptin analysis was obtained while another test for diagnosis or check-up was needed in clinic; therefore no extra venipuncture was imposed on individuals. Families and patients were not charged for leptin testing.

\section{Patients}

We studied 43 patients with CF aged from 3 months to 10 years. They were recruited from the Cystic Fibrosis Outpatient Clinic of the Children's Medical Center Hospital. Diagnosis of CF was confirmed based on two positive sweat chloride tests and in a few (6 cases) confirmed by genetic analysis (PCR). All CF patients were studied when they were clinically stable and without evidence of acute pulmonary exacerbation. All CF patients with pancreatic insufficiency received pancreatic enzyme replacement therapy and had no obvious signs or clinical symptoms and were not pancreatic insufficient and parents have been specifically instructed on nutritional requirements of them. Patients with pancreatic insufficiency or acute respiratory illness were not entered in the study.

Forty-three healthy control subjects, matched for age and sex, were enrolled as controls. Controls were visited in the general outpatient clinic of the Children's Medical Center Hospital for an annual check-up. The sample size was determined according to specific statistical formulas with consideration of previous studies [20].

All individuals in both patient and control groups were divided into three groups based on age: 3 to 12 months, 13 to 48 months, and 49 to 120 months age.

All the participants underwent physical examination. Body weight and height were measured. Body mass index was calculated (weight in kilograms divided by the square of height in meters). Children had no gastrointestinal issues that would indicate malabsorption.

\section{Assessments}

Venous blood samples were obtained from CF patients and healthy controls. Serum was separated and stored at $-20^{\circ} \mathrm{C}$ until assayed for leptin. Serum leptin levels were measured applying a solid phase enzyme-linked immunosorbent assay (ELISA) based on the sandwich principle. All steps were performed according to manufacturer's instructions (Leptin (Sandwich) ELISA kit, DRG Instruments $\mathrm{GmbH}$, Germany)

\section{Data analyses}

The results are expressed as mean \pm SEM. Data were tested for normality using the Kolmogorov- 
Smirnov test using $p=0.05$ threshold for rejection of normality. Statistical analysis was performed using SPSS version 16.0.1 (SPSS Inc., Chicago, IL, U.S.A.). The statistical differences between proportions were determined by $\chi^{2}$ analysis; the statistical significance of differences between means was determined by Mann-Whitney $U$ analysis for nonparametric and independent Student's $t$-test analysis for normal values. Correlation between numeric data was analyzed using linear regression. A $p$ value $<0.05$ was considered as significant.

\section{Results}

Forty-three CF patients ( 23 males and $20 \mathrm{fe-}$ males) and 43 controls ( 26 males and 17 females) were enrolled in the study. Mean age of patients was $41.19 \pm 37.90$ months, and mean age of controls was $46.49 \pm 41.50$ months $(p=0.660)$. The characteristics of the two groups are presented in Table I. There was no difference between the groups in age or gender distribution.

The plasma level of leptin in CF patients was significantly higher than in the control group (mean $25-75 \%$ : 50.9 vs. $36, p=0.006$ ). Body mass index level in CF patients is significantly lower than in the control group ( $p<0.001)$; also the prevalence of underweight $\left(\mathrm{BMI}<20 \mathrm{~kg} / \mathrm{m}^{2}\right)$ in CF patients is higher than in the control group ( $p<0.001)$. The mean body weight in the control group is also higher than CF patients $(p=0.001)$ but there was no difference in height between the groups. The albumin plasma level in CF patients was lower than in the control group $(p=0.001)$. There was no significant difference between males and females in BMI, albumin or ghrelin levels. According to the regression analysis there was no statistically significant correlation between plasma leptin level and serum albumin, weight, height or BMI values in CF patients or the control group.

Leptin levels differ by sex among CF patients. Male patients' leptin level was $27.16 \pm 33.75 \mu \mathrm{g} /$, which was significantly higher $(p=0.032)$ than that
Table I. Anthropometric characteristics in CF patients and healthy control group (mean $\pm \mathrm{SE}$ )

\begin{tabular}{|lccc|}
\hline Parameter & CF $(n=43)$ & Normal $(n=43)$ & Value of $p$ \\
\hline Albumin & $4.5 \pm 1$ & $4.8 \pm 0.09$ & 0.001 \\
\hline BMI & $15.1 \pm 0.5$ & $21.6 \pm 0.6$ & $<0.001$ \\
\hline Weight & $12.5 \pm 1.4$ & $20.5 \pm 1.7$ & 0.001 \\
\hline Height & $85.3 \pm 4.4$ & $95.23 \pm 4.5$ & Not significant \\
\hline
\end{tabular}

of female patients (mean: $13.85 \pm 16.79 \mu \mathrm{g} / \mathrm{l}$ ). On the other hand, there were no significant differences between girls and boys in controls, although there was a trend towards lower values in boys.

Interestingly, leptin values in CF boys is significantly higher than their sex-matched controls $(p<0.001)$, while leptin values in girls do not differ between patients and controls $(p=0.408)$.

Table II shows a detailed comparison of BMI and leptin levels between CF patients and controls. There is a strong trend towards increased leptin in CF patients aged 13-48 months compared to matched controls (Table II).

\section{Discussion}

Normally starvation leads to a decrease in leptin levels. However, weight loss associated with CF is different from that of starvation [5].

Previous studies resulted in conflicting data about leptin level and its role in body weight of CF patients. Direct comparison is difficult as prior studies included small numbers of patients, and different CF and control populations with different age and from various geographical regions and ethnic groups.

We performed age subgrouping in our patient and control groups. Body mass indexvalues in all three subgroups were significantly different between patients and controls. Leptin levels for normal children have not been established widely in the literature so we could only compare it between two groups. Leptin levels differ in general between

Table II. Comparison of BMI and leptin level between CF patients and controls

\begin{tabular}{|c|c|c|c|}
\hline Parameter & $\begin{array}{l}\text { Cystic fibrosis patients } \\
(n=43 ; 23 \text { boys } / 20 \text { girls })\end{array}$ & $\begin{array}{c}\text { Controls } \\
(n=43 ; 26 \text { boys } / 17 \text { girls })\end{array}$ & Value of $p$ \\
\hline Body mass index & Mean: $15.16 \pm 3.33$ & Mean: $21.57 \pm 4.32$ & $<0.001$ \\
\hline Leptin $[\mu \mathrm{g} / \mathrm{l}]$ & Mean: $20.97 \pm 27.74$ & Mean: $6.42 \pm 7.64$ & 0.02 \\
\hline Leptin in $1^{\text {st }}$ age group (3-12 months old) $(n)$ & Mean: $25.53 \pm 31.3(17)$ & Mean: $4.64 \pm 5.32(15)$ & 0.076 \\
\hline $\begin{array}{l}\text { Leptin in } 2^{\text {nd }} \text { age group (13-48 months old) }(n) \\
{[\mu \mathrm{g} / \mathrm{l}]}\end{array}$ & Mean: $16.00 \pm 22.14(8)$ & Mean: $4.85 \pm 5.86(15)$ & 0.016 \\
\hline $\begin{array}{l}\text { Leptin in } 3^{\text {rd }} \text { age group (49-120 months old) }(n) \\
{[\mu \mathrm{g} / \mathrm{l}]}\end{array}$ & Mean: $18.86 \pm 27.11(18)$ & Mean: $10.10 \pm 10.39(13)$ & 0.234 \\
\hline Leptin level in boys $[\mu \mathrm{g} / \mathrm{l}]$ & Mean: $27.16 \pm 33.75$ & Mean: $5.15 \pm 6.41$ & $<0.001$ \\
\hline Leptin level in girls $[\mu \mathrm{g} / \mathrm{l}]$ & Mean: $13.85 \pm 16.79$ & Mean: $8.37 \pm 9.08$ & 0.408 \\
\hline
\end{tabular}


CF patients and controls; however, its levels were significantly higher in only the youngest patients aged 3-12 months than their age-matched controls and there were no significant differences in leptin values between patients and controls in other age groups.

Children and adolescent CF patients were evaluated in studies performed by Ahmed et al. (133 CF patients, 77 males and 76 females, with a median age of 5.99 (2.27-17.98) years and 40 controls, 20 males and 20 females, aged 8.6-10.2 years), Stylianou et al. (14 CF patients, 7 males and 7 females, with mean age of $19.06 \pm 5.08$ years and 20 controls, 10 males and 10 females, with mean age of $19.05 \pm 5.69$ years) and Boguszewski et al. (26 CF children, aged 5.0-15.5 years and 33 controls with mean age of 9.4 years) [19-21].

British [19] and Greek [20] CF patients demonstrated higher levels of leptin than controls in the former two studies and their results were in parallel with our results, while the latter reported lower values of leptin among CF Brazilian children compared to controls [21]. This discrepancy may be related to the diverse nature of the disease, as we know CF is the result of different mutations and ethnic differences plus environmental factors such as nutritional status may affect its level, too.

The Schmitt-Grohé et al. study included children and adults altogether (1-43 years old). They showed lower leptin levels among CF patients. The lower leptin level could be due to the age heterogeneity [23]. Cohen et al. and Arumugam et al. both assessed American CF adults [5, 22]. Arumugam et al. found no difference between adult patients and controls (27 CF patients 20-30 years and 12 control subjects 21-29 years), but in the Cohen et al. study, the patients with severe CF had significantly lower leptin levels compared to controls (74 CF adults and 20 controls, $10 \mathrm{M}$ and $10 \mathrm{~F}$ ), CF patients with mild or moderate symptoms. They suggested that the lower leptin value in patients is a consequence of weight loss and is not the cause of it [5].

Among the studies evaluating leptin in CF patients, only Schmitt-Grohé et al. (44 subjects, range 1 to 43 years, $28 \mathrm{M}$ and $16 \mathrm{~F}$, and 22 controls range 1 to 40 years, $14 \mathrm{M}$ and $8 \mathrm{~F}$ ) consider the genetic factor in the patients [23]. They only assessed homozygosity for $\Delta \mathrm{F} 508$ (the most important and most lethal genotype leading to CF in the CFTR gene). The disease has a wide phenotypic spectrum directly associated with the patients' genotype. Heterogenic phenotypes are observed in different geographical regions as the frequency of mutations in CFTR varies amongst different ethnicities. The other five studies and our study evaluated patients without genetic subgrouping in the United States, Greece, the United Kingdom, Brazil and Iran [5, 1922]. There is a strong trend towards increased lep- tin in CF patients 13-48 months old compared to matched controls (Table II), but variability was also increased. A larger sample size would probably detect significant differences in this type of population. Further studies are required on specific genotypes to reveal the probable correlation of genetic factors with phenotypic characteristics such as BMI and leptin levels in different ethnic groups and these differences may be due to different mutations and genotypes leading to different phenotypes.

Unexpectedly, leptin levels were significantly higher in our male patients than both female CF patients and male controls. Leptin values in girls did not differ between patients and controls. The mean age of CF male patients was lower than male and female controls, as well as female patients. Although it was not significant, larger sample sizes could clarify the probable impact of gender on leptin levels in these patients. Our results are in conflict with the three previous studies that considered gender in their analysis. Schmitt-Grohé et al. found that leptin levels are significantly lower in CF patients without predominance in either gender [23]. Male patients had lower leptin levels than female patients in the Stylianou et al. and Arumugam et al. studies $[20,22]$. It was suggested that leptin regulation is gender-related. It has been observed that leptin expression is sexually dimorphic. Leptin expression inhibition by testosterone and augmentation by ovarian sex steroids is associated with BMI-adjusted higher leptin levels in women than in men [14, 24].

The increased leptin levels in toddlers may contribute to malnutrition in CF patients early in life before the diagnosis of CF and beginning of nutritional aids. One of the rationales for newborn screening has been early malnutrition in undiagnosed, untreated young children - perhaps this is one of the mechanisms.

Our study has some limitation such as although we performed it in Iran, our patients belonged to different parts of our country and various ethnic groups, which may cause some variation in disease pattern and presentation. Another limitation was that the patients' CFTR genotypes were not available.

Also the nutritional status and level of taking care of children by parents were different, so in spite of our trying to make a homogenized research environment, it surely is not the ideal one.

Another limitation was studying stable patients whose leptin level cannot reflect the real level in different periods of the disease course. Serial measuring, especially in stable and disease phases, may aid more in assessing its influence on weight. Also the lower BMI in CF children itself is disturbing and may contribute to the elevated leptin level, and even if they were taking pancreatic enzymes, they could still have malnutrition. 
Leptin level in our patients was significantly higher than in controls and this higher level may be related to its inflammatory cytokine property which can suppress the appetite of CF children.

In addition, in contrast to the previous studies, male patients had higher levels of leptin than females. It seems that leptin levels during the first year of life are higher in CF patients, and by growing older, patients who survive the risky period of infancy can better regulate the leptin levels in their body and the physiologic regulation of it is preserved despite weight loss in CF patients.

Further studies are required on specific genotypes, as well as gender and age subgroups, to reveal the probable correlation of these factors with phenotypic characteristics such as BMI and leptin levels in CF patients from different ethnic groups.

\section{Acknowledgments}

This study was the postgraduate thesis of Dr. Ehsan Sadrian and financial support was provided by Tehran University of Medical Sciences. We would like to thank Miss Leila Kashi and Mrs. Heshmat Irani for their technical support.

\section{References}

1. Dodge JA, Morison S, Lewis PA, et al. Incidence, population, and survival of cystic fibrosis in the UK, 1968-95. UK Cystic Fibrosis Survey Management Committee. Arch Dis Child Arch Dis Child 1997; 77: 493-6.

2. Morison S, Dodge JA, Cole TJ, et al. Height and weight in cystic fibrosis: a cross sectional study. UK Cystic Fibrosis Survey Management Committee. Arch Dis Child 1997; 77 : 497-500.

3. Cystic Fibrosis Patient Registry. Annual data report 2003. Bethesda, Maryland, USA: Cystic Fibrosis Foundation 2004.

4. Milla CE. Nutrition and lung disease in cystic fibrosis. Clin Chest Med 2007; 28: 319-30.

5. Cohen RI, Tsang D, Koenig S, Wilson D, McCloskey T, Chandra S. Plasma ghrelin and leptin in adult cystic fibrosis patients. J Cyst Fibros 2008; 7: 398-402.

6. Dixit VD, Schaffer EM, Pyle RS, et al. Ghrelin inhibits leptin- and activation-induced proinflammatory cytokine expression by human monocytes and T cells. J Clin Invest 2004; 114: 57-66.

7. Matarese G, Moschos S, Mantzoros CS. Leptin in immunology. J Immunol 2005; 174: 3137-42.

8. Zhang Y, Proenca R, Maffei M, Barone M, Leopold L, Friedman JM. Positional cloning of the mouse obese gene and its human homologue. Nature 1994; 372: 425-32.

9. Rohner-Jeanrenaud F, Jeanrenaud B. Obesity, leptin and the brain. N Engl J Med 1996; 334: 324-5.

10. Farooqi IS, Matarese G, Lord GM, et al. Beneficial effects of leptin on obesity, $T$ cell hyporesponsiveness, and neuroendocrine/metabolic dysfunction of human congenital leptin deficiency. J Clin Invest 2002; 110: 1093-103.

11. Bray GA, York DA. Leptin and clinical medicine: a new piece in the puzzle of obesity. J Clin Endocrinol Metab 1997; 82: 2771-6.

12. Ahima RS, Prabakaran D, Mantzoros C, et al. Role of leptin in the neuroendocrine response to fasting. Nature 1996; 382: 250-2.
13. Chan JL, Heist K, DePaoli AM, Veldhuis JD, Mantzoros CS. The role of falling leptin levels in the neuroendocrine and metabolic adaptation to short-term starvation in healthy men. J Clin Invest 2003; 111: 1409-21.

14. Lago R, Gómez R, Lago F, Gómez-Reino J, Gualillo O. Leptin beyond body weight regulation: current concepts concerning its role in immune function and inflammation. Cell Immunol 2008; 252: 139-45.

15. Otero M, Lago R, Gomez R, et al. Towards a pro-inflammatory and immunomodulatory emerging role of leptin. Rheumatology (Oxford) 2006; 45: 944-50.

16. Boden G, Chen X, Kolaczynski JW, Polansky M. Effects of prolonged hyperinsulinemia on serum leptin in normal human subjects. J Clin Invest 1997; 100: 1107-13.

17. Zakrzewska KE, Cusin I, Sainsbury A, Rohner-Jeanrenaud F, Jeanrenaud B. Glucocorticoids as counterregulatory hormones of leptin: toward an understanding of leptin resistance. Diabetes 1997; 46: 717-9.

18. Monteleone P, Fabrazzo M, Tortorella A, Fuschino A, Maj M. Opposite modifications in circulating leptin and soluble leptin receptor across the eating disorder spectrum. Mol Psychiatry 2002; 7: 641-6.

19. Ahmed ML, Ong KK, Thomson AH, Dunger DB. Reduced gains in fat and fat-free mass, and elevated leptin levels in children and adolescents with cystic fibrosis. Acta Paediatr 2004; 93: 1185-91.

20. Stylianou C, Galli-Tsinopoulou A, Koliakos G, Fotoulaki M, Nousia-Arvanitakis S. Ghrelin and leptin levels in young adults with cystic fibrosis: relationship with body fat. J Cyst Fibros 2007; 6: 293-6.

21. Boguszewski MC, Kamoi TO, Bento Radominski R, et al. Insulin-like growth factor-1, leptin, body composition, and clinical status interactions in children with cystic fibrosis. Horm Res 2007; 67: 250-6.

22. Arumugam R, LeBlanc A, Seilheimer DK, Hardin DS. Serum leptin and IGF-I levels in cystic fibrosis. Endocr Res 1998; 24: 247-57.

23. Schmitt-Grohé S, Hippe V, Igel M, et al. Serum leptin and cytokines in whole blood in relation to clinical and nutritional status in cystic fibrosis. J Pediatr Gastroenterol Nutr 2006; 43: 228-33.

24. Blum WF, Englaro P, Hanitsch S, et al. Plasma leptin levels in healthy children and adolescents: dependence on body mass index, body fat mass, gender, pubertal stage, and testosterone. J Clin Endocrinol Metab 1997; 82: 2904-10. 